\title{
2D Echocardiographic features in low T3 syndrome in chronic heart failure
}

\author{
N. Arun Kumar', Y. L. Shivamurthy², V. Mohan Kumar³, S. S. Ramesh4, A. G. Ravi Shankar \\ M. M. Basavaraju ${ }^{4}$, S. K. Yathish', S. M. Manjunatha ${ }^{5}$ \\ ${ }^{1}$ Senior Resident, Dept. of General Medicine, ESIC MC \& PGIMSR, Bangalore, ${ }^{2}$ Manipal Hospital, Bangalore, ${ }^{3}$ Vaatsalya Hospital, \\ Mandya, ${ }^{4}$ Mysore Medical College, ${ }^{5}$ NRS Medical College, Kolkata
}

Background: Thyroid abnormalities are common in chronic heart failure. Severity of heart failure rises by several fold in patients with thyroid dysfunction. Objectives: The purpose of this prospective study is to determine the correlation between low T3 syndrome and chronic heart failure with 2D echocardiography features \& predicting the severity of chronic heart failure. Methods: In this descriptive, prospective cross sectional study, all patients who presented to the department of medicine with chronic heart failure during this study period of 12 months from January 2010-December 2011 in K.R.Hospital, Mysore were included. Patients were grouped into Low T3 chronic heart failure, hypothyroid chronic heart failure and chronic heart failure. Results: Mean age of low T3 chronic heart failure patients was higher than other two groups $[60.50 \pm 6.15(\mathrm{SD})$ years, Systolic dysfunction on 2D Echo was more in low T3 dilated cardiomyopathy (20\%), Diastolic dysfunction on 2D Echo was more in low T3 dilated cardiomyopathy group (30\%), Pericardial effusion was seen in more number of patients with low T3 dilated cardiomyopathy (10\%).Global hypokinesia was seen in more number of patients with low T3 dilated cardiomyopathy (30\%).Segmental hypokinesia was seen in more number of patients with low T3 dilated cardiomyopathy (3\%). Mean ejection fraction was seen in more number of patients with low T3 dilated cardiomyopathy [36.78 \pm 5.08 (SD) \%]. Mean ejection fraction was lower in low T3 dilated cardiomyopathy [34.8 \pm 3.293 (SD) \%].The high pulmonary artery systolic pressure was seen in more number of patients in low T3 dilated cardiomyopathy (70\%).Conclusion: There is significant percentage of chronic heart failure patients having low T3 alone as biochemical parameter. It is important to recognize patients with chronic heart failure as it is associated with increased severity of heart failure.

Key words: Chronic heart failure, Low T3 syndrome, Dilated cardiomyopathy, 2D-echocardiography, Ejection fraction

\section{INTRODUCTION}

Clinical and experimental evidences have shown that $\mathrm{T} 3$ plays a major role in modulating heart rate and cardiac contractility as well as arterial peripheral resistance. T3 actions are carried out by binding with specific nuclear receptors that regulate responsive genes encoding for structural and functional cardiac proteins; direct, extra-nuclear, non transcriptional effects have also been described. ${ }^{1,2}$

The cardiovascular system is one of the most important targets on which thyroid hormones act. More than $80 \%$
Access this article online

Website:

http://nepjol.info/index.php/AJMS 
This low-T3 syndrome has commonly been interpreted by the medical community as a euthyroid sick syndrome, an adaptive compensatory and thus beneficial response that decreases energy consumption in diseased states. This interpretation, however, has recently been questioned. Although clinical data documented the benefit gained from treating patients with synthetic thyroid hormones. ${ }^{11-14}$

A new study in rats is giving researchers hope that more aggressive treatment of hypothyroidism and borderline hypothyroidism will result in a reduction of chronic heart failure in human beings. ${ }^{15-17}$

While further research is needed, results from a recent study entitled, "Low thyroid function leads to cardiac atrophy with chamber dilation, impaired myocardial blood flow, loss of arterioles, and severe systolic dysfunction," suggest that low thyroid function has the potential to cause heart failure. ${ }^{18,19}$

Low thyroid function alone induced in rats eventually can cause heart failure. "It was also discovered that low thyroid function severely impaired cardiac blood flow due to a dramatic loss of the hearts small blood vessels (arterioles). Within six weeks after inducing low thyroid function in rats, half of the heart's small arterioles were gone." hypothyroidism led to severe, progressive contractile dysfunction, chamber enlargement, and ventricular wall thinning despite a reduction in cardiac mass. Hypothyroidism induced in the rats also resulted in impaired myocardial blood flow due to a dramatic loss of arterioles. As a result, it identified two new mechanisms by which low thyroid function may lead to heart failure. ${ }^{20}$

The results suggested that individuals with borderline hypothyroidism may also have similar cardiac changes. Clearly more research is needed to determine if these detrimental cardiac changes occur in humans and if treatment of heart patients with borderline hypothyroidism will lead to improved outcomes. ${ }^{20}$

\section{METHODOLOGY}

Study design: Prospective study. Sample Size: 50 cases over a span of 12 months from January 2010-December 2011 in K.R.Hospital, Mysore.

\section{Method of collection of data}

The data for the purpose of the study was collected in a predesigned and pretested proforma, ethical committee clearance and consent was obtained. Proforma included various socioeconomic parameters like age, sex, occupation, religion, etc. About 50 cases were selected on the basis of the simple Random sampling method.

\section{Statistical analysis}

Data was analyzed ANOVA, factor analysis and Chisquare test. Data were entered into Microsoft Excel 2007, and statistical analysis was performed using the statistical package for social sciences (SPSS) version 20 (SPSS Inc. Chicago,USA). Data were presented as Mean \pm SD.

\section{Inclusion criteria}

Patients with chronic heart failure.

\section{Exclusion criteria}

Included clinical evidence of sepsis or cachexia or Concomitant presence of any predominant severe systemic disease including severe anaemia $\mathrm{Hb} \%<5 \mathrm{~g} \%$.Other major surgical procedures performed before or within 6 months after the time of thyroid sampling.

Routine investigations, to assess thyroid function and to clinically diagnose chronic heart failure. Investigations are as follows:The thyroid function profile: After rapid centrifugation of a venous sample, Total T3 (TT3), fT3, Total T4 (TT4), fT4 and TSH was measured. Patient was physically assessed, radiographic investigations were carried out \& 2D echocardiography was done for diagnosing \& characterizing chronic heart failure.

All these methods, however, have major limitations when used independently. Scoring systems that combine several of the measures discussed below have been developed for use in population-based studies for chronic heart failure.

\section{RESULTS}

In this study titled "2D ECHOCARDIOGRAPHIC FEATURES IN LOW T3 SYNDROME IN CHF” A descriptive, prospective cross sectional study comprising of $50 \mathrm{CHF}$ patients admitted to KR hospital, Mysore who are studied under three groups namely Hypothyroid CHF, Low T3 CHF \& CHF only.

Table 1 shows among 50 CHF patients 29 patients (58\%) are hypothyroid CHF, 10 patients $(20 \%)$ have low T3 CHF alone and 11 patients $(22 \%)$ are CHF only in present study.

Table 2 shows mean age for Low T3 CHF patients was $60.50 \pm 6.15(\mathrm{SD})$ years which was higher when compared to mean age of CHF only patients which was $59.91 \pm 5.99$ (SD) years and $54.9 \pm 5.49$ (SD) years for hypo thyroid CHF patients in the present study which shows that low T3 CHF occurs in more elderly patients with CHF. The mean age of CHF patients in the present study was $58.43 \pm 5.87$ (SD) years. 
Table 3 shows that systolic dysfunction was seen in more number of patients of hypothyroid CHF group (31.03\%), when compared to $20 \%$ in low T3 CHF group \& $9.09 \%$ in CHF only group in present study, which was statistically not significant $(\mathrm{p}<0.333)$.

Table 3 shows that diastolic dysfunction was seen in more number of patients in low T3 CHF group (30\%), when compared to hypothyroid CHF group in whom it was $17.24 \%$, and CHF only group in whom it was $9.09 \%$ in present study, which was statistically not significant $(\mathrm{p}<0.455)$.

Table 3 shows that pericardial effusion was seen in more number of patients in low T3 CHF group (10\%), when compared to $9.09 \%$ in CHF only group \& none in hypothyroid CHF group in present study, which was statistically not significant $(\mathrm{p}<0.236)$.

Table 3 shows that Global hypokinesia was seen in more number of patients in hypothyroid CHF group (48.28\%), when compared to $45.45 \%$ in CHF only group and $30 \%$ in low T3 CHF group in present study, which was statistically not significant $(p<0.6)$.

Table 3 shows that segmental hypokinesia was seen in more number of patients with hypothyroid CHF group $(51.72 \%)$, when compared to $45.45 \%$ in CHF only group and 30\% in Low T3 CHF group in present study, which was statistically not significant $(\mathrm{p}<0.490)$.

Table 3 shows that high pulmonary artery systolic pressure in low T3 group CHF group was seen in more number of patients $(70 \%)$, when compared to $10.34 \%$ in hypothyroid CHF group and $9.09 \%$ in CHF only group in present study, which was statistically significant $(\mathrm{P}<0.000)$. This shows that pulmonary hypertension was seen in more number of patients with low T3 CHF.

Table 4 shows that patients with Low T3 CHF had a low

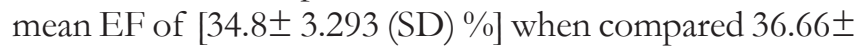
5.563 (SD) \% in hypothyroid CHF group \& $38.91 \pm 4.592$ (SD) $\%$ in CHF Only group in present study, which was statistically not significant $(\mathrm{p}<0.178)$. The mean EF of patients with CHF in present study was $36.78 \pm 5.08$ (SD) $\%$.

Table 5 shows majority of patients with hypothyroid $\mathrm{CHF}$ were within the age group of $55-60 \mathrm{yrs}(34.48 \%)$ and patients with hypothyroid CHF had low mean EF $36.6 \pm 5.5$ (SD) \% with age group of $60-65 \mathrm{yrs}$ in the present study.

There was equal distribution of patients with low T3 CHF in age group 55-60yrs (30\%), 60-65yrs (30\%) \& 65-70yrs
(30\%), patients with low T3 CHF had low mean EF 32 2.3 (SD) $\%$ with age group of $50-55 \mathrm{yrs}$ in the present study.

Majority of patients with CHF only are within age group of $60-65 y$ rs $(36.36 \%)$. The patients with CHF only had low mean $\mathrm{EF} 34 \pm 3$ (SD) \% with age group of $65-70 \mathrm{yrs}$ in the present study.

The mean EF of patient with low T3 was lower [34.8 \pm 3.2 (SD) \%] when compared to $36.66 \pm 5.5$ (SD) $\%$ in hypo thyroid $\mathrm{CHF}$ and $38.9 \pm 5$ (SD) $\%$ in $\mathrm{CHF}$ alone in the present study which was statistically not significant $(\mathrm{p}<0.178)$.

\begin{tabular}{lcc}
$\begin{array}{l}\text { Table 1: Prevalence of hypothyroidism, low T3 } \\
\text { and CHF only in present study }\end{array}$ \\
\hline Group & Number of patients & Percentage (\%) \\
\hline Hypothyroid & 29 & 58 \\
Low T3 & 10 & 20 \\
CHF only & 11 & 22 \\
Total & 50 & 100 \\
\hline
\end{tabular}

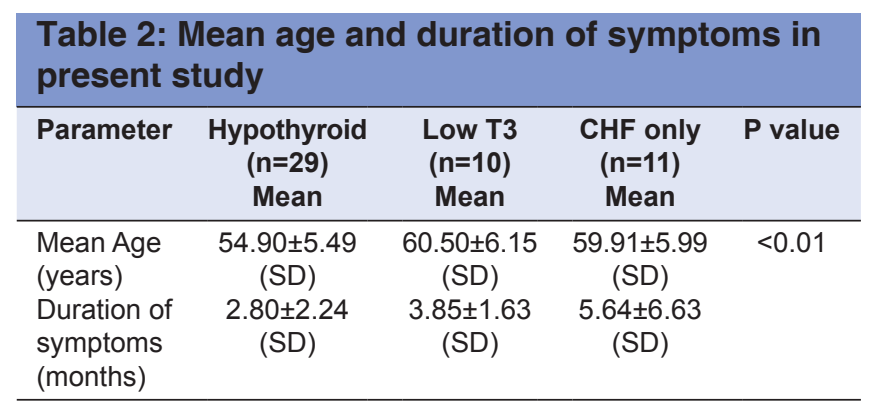

\begin{tabular}{|c|c|c|c|c|}
\hline $\begin{array}{l}\text { 2D-Echo } \\
\text { Changes }\end{array}$ & $\begin{array}{l}\text { Hypothyroid } \\
(n=29), \\
\text { No }(\%) .\end{array}$ & $\begin{array}{c}\text { Low } \\
\text { T3 (n=10), } \\
\text { No(\%). }\end{array}$ & $\begin{array}{c}\text { CHF only } \\
(n=11), \\
\text { No (\%). }\end{array}$ & $P$ value \\
\hline Systolic dysfunction & $9(31.03 \%)$ & $2(20 \%)$ & $1(9.09 \%)$ & $<0.333$ \\
\hline Diastolic ysfunction & $5(17.24 \%)$ & $3(30 \%)$ & $1(9.09 \%)$ & $<0.455$ \\
\hline Pericardial effusion & $0(0 \%)$ & $1(10 \%)$ & $1(9.09 \%)$ & $<0.236$ \\
\hline Global hypokinesia & $14(48.28 \%)$ & $3(30 \%)$ & $5(45.45 \%)$ & $<0.60$ \\
\hline $\begin{array}{l}\text { Segmental } \\
\text { hypokinesia }\end{array}$ & 15 (51.72\%) & $3(30 \%)$ & $5(45.45 \%)$ & $<0.49$ \\
\hline $\begin{array}{l}\text { High pulmonary } \\
\text { artery systolic } \\
\text { pressure }\end{array}$ & $3(10.34 \%)$ & $7(70 \%)$ & $1(9.09 \%)$ & $<0.00$ \\
\hline
\end{tabular}

\begin{tabular}{|c|c|}
\hline Groups & Mean EF (in \%) \\
\hline Hypothyroid $(n=29)$ & $36.66 \pm 5.563(\mathrm{SD})$ \\
\hline Low T3 $(n=10)$ & $34.8 \pm 3.293$ (SD) \\
\hline CHF Only $(n=11)$ & $38.91 \pm 4.592(\mathrm{SD})$ \\
\hline Total $(n=50)$ & $36.78 \pm 5.08$ (SD) \\
\hline
\end{tabular}




\begin{tabular}{|c|c|c|c|c|c|c|}
\hline \multirow{2}{*}{$\begin{array}{l}\text { Age group } \\
\text { in years }\end{array}$} & \multicolumn{2}{|c|}{ Hypothyroid $(n=29)$} & \multicolumn{2}{|c|}{ Low T3 $(n=10)$} & \multicolumn{2}{|c|}{ CHF only (n=11) } \\
\hline & No (\%) & Mean EF (in \%) & No (\%) & Mean EF (in \%) & No (\%) & Mean EF (in \%) \\
\hline $45-50$ & $6(20.69 \%)$ & $36.3 \pm 4.3(\mathrm{SD})$ & - & - & $1(9.09)$ & $40 \pm 1.8(S D)$ \\
\hline $50-55$ & $7(24.13 \%)$ & $40.1 \pm 4.2(\mathrm{SD})$ & $1(10 \%)$ & $32 \pm 2.3(\mathrm{SD})$ & $1(9.09)$ & $44 \pm 2.2(\mathrm{SD})$ \\
\hline $55-60$ & $10(34.48 \%)$ & $36.7 \pm 7.1$ (SD) & $3(30 \%)$ & $35.3 \pm 4.2(\mathrm{SD})$ & $3(27.27)$ & $38 \pm 5.8$ (SD) \\
\hline $60-65$ & $4(13.79 \%)$ & $36.2 \pm 6.6(\mathrm{SD})$ & $3(30 \%)$ & $35.3 \pm 4.6(\mathrm{SD})$ & $4(36.36)$ & $41 \pm 4.3$ (SD) \\
\hline $65-70$ & $2(6.89 \%)$ & $41 \pm 1.8$ (SD) & $3(30 \%)$ & $34.6 \pm 1.4(\mathrm{SD})$ & $2(18.18)$ & $34 \pm 3(S D)$ \\
\hline Total & 29 & $36.66 \pm 5.5$ (SD) & 10 & $34.8 \pm 3.2(\mathrm{SD})$ & $11(100)$ & $38.91 \pm 4.592(\mathrm{SD})$ \\
\hline
\end{tabular}

\section{DISCUSSION}

Low thyroid hormone concentrations, in particular low serum $\mathrm{T} 3$ concentrations, are a common finding in patients with non thyroidal illnesses, including cardiac disorders. Its pathophysiological role is not well understood, although the common belief is in favor of an adaptive mechanism to preserve energy. Nonetheless, based on the knowledge of the fundamental actions of $\mathrm{T} 3$ on both the heart and vessels, a direct relationship between low circulating levels of T3 and adverse prognosis of cardiac patients has represented an attractive hypothesis in the last few years. In this respect, it has been postulated that the low T3 state may produce a hypothyroid-like syndrome that contributes to the worsening or exacerbation of the intrinsic cardiac disease. ${ }^{1}$

The low T3 circulatory levels were found in $20 \%$ of patients with $\mathrm{CHF}$ in the present study. Mean age for Low T3 CHF patients was $60.50 \pm 6.15(\mathrm{SD})$ years which was higher when compared to mean age of CHF only patients which was $59.91 \pm 5.99(\mathrm{SD})$ years and $54.9 \pm 5.49(\mathrm{SD})$ years for hypo thyroid CHF patients in the present study which shows that low T3 CHF occurs in more elderly patients with CHF. The mean age of CHF patients in the present study was $58.43 \pm 5.87(\mathrm{SD})$ years which was comparable to Joao Paulo Solano, George Marzouka and ACC 2011..$^{2-5}$

The systolic dysfunction on 2D Echo was more in low T3 CHF $(20 \%)$ when compared to CHF only group $(9.09 \%)$ but was lesser than hypothyroid CHF group (31.03\%). The diastolic dysfunction was more in low T3 CHF (30\%) when compared to other two groups. Pericardial effusion was seen in more number of patients with low T3 CHF (10\%) when compared to other two groups. The global hypokinesia was seen in less number of patients with low T3 CHF group $(30 \%)$ when compared to other two groups. The segmental hypokinesia was seen in less number of patients with low T3 CHF group (30\%) when compared to other two groups.

The mean ejection fraction of patients with CHF in the present study was $[36.78 \pm 5.08(\mathrm{SD}) \%]$ which was comparable to Deborah and Joa Paulo Solano, George Marzouka. ${ }^{2-5}$
Table 6 shows the mean ejection fraction was lower in patient with low T3 CHF [34.8 23.293 (SD) \%] when compared to other two groups.

This showed that the severity of heart failure was higher in patients with low T3 CHF and incidence of IHD in the form of global hypokinesia and segmental hypokinesia was lesser in patients with low T3 CHF.

The high pulmonary artery systolic pressure was seen in more number $(70 \%)$ of patients with low T3 CHF group when compared to other two groups; this shows increase in severity of right heart failure in patients with low T3 CHF in the present study.

\section{CONCLUSION}

There is significant percentage of CHF patients having low T3 alone as biochemical parameter. It is important to recognize this condition in patients with $\mathrm{CHF}$ as it is associated with increased severity of heart failure.

\section{Key message}

- Low T3 circulatory levels were found in $20 \%$ of patients of $\mathrm{CHF}$ in present study.

- Mean age of CHF patients in present study was $58.43 \pm 5.87(\mathrm{SD})$ years.

- Mean age of low T3 CHF patients was higher [60.50 $\pm 6.15(\mathrm{SD})$ years] when compared to other two groups.

- Systolic dysfunction on 2D Echo was more in low T3 CHF group $(20 \%)$

- Diastolic dysfunction on 2D Echo was more in low T3 CHF group (30\%)

- Pericardial effusion was seen in more number of patients with low T3 CHF (10\%).

- Global hypokinesia was seen in more number of patients with low T3 CHF (30\%).

- Segmental hypokinesia was seen in more number of patients with low T3 CHF (3\%).

- Mean ejection fraction was seen in more number of patients with low T3 CHF [36.78 5 5.08(SD)\%].

- Mean ejection fraction was lower in low T3 CHF $[34.8 \pm 3.293(\mathrm{SD}) \%]$. 
- The high pulmonary artery systolic pressure was seen in more number of patients in low $\mathrm{T} 3 \mathrm{CHF}$ $(70 \%)$.

\section{ACKNOWLEDGEMENT}

We would like to cordially thank Department of General Medicine, Mysore Medical college and reaserch Institute for supporting this study.

\section{REFERENCES}

1. Polikar R, Burger AG, Scherrer $U$ and Nicod P. The thyroid and the heart. Circulation 1993; 87: 1435-1441.

2. Klein I and Ojamaa K. Mechanism of disease: thyroid hormone and the cardiovascular system. N Engl J Med. 2001; 344: 501509.

3. Pilo A, lervasi G, Vitek F, Ferdeghini M, Cazzuola F and Bianchi R. Thyroidal and peripheral production of 3,5,3'-triiodothyronine in humans by multicompartmental analysis. Am J Physiol. 1990; 258: E715-E726.

4. Franklyn JA, Gammage MD, Ramsden DB and Sheppard MC. Thyroid status in patients after acute myocardial infarction. Clin Sci (Colch). 1984; 67: 585-590.

5. Wiersinga WM, Lie $\mathrm{KI}$ and Toubler JL. Thyroid hormones in acute myocardial infarction. Clin Endocrinol. 1981; 14: 367-374.

6. Hamilton MA, Stevenson LW, Luu M and Walden JA. Altered thyroid hormone metabolism in advanced heart failure. J Am Coll Cardiol. 1990; 16: 91-95.

7. Klemperer JD, Klein I, Gomez M, Helm RE, Ojamaa K, Thomas SJ, et al. Thyroid hormone treatment after coronary artery bypass surgery. N Engl J Med 1995; 333: 1522-1527.

8. Murzi B, lervasi G, Masini S, Moschetti R, Vanini V, Zucchelli G, et al. Thyroid hormones homeostasis in pediatric patients during and after cardiopulmonary by-pass. Ann Thorac Surg 1995; 59: 481-485.
9. Holland FW, Brown PS, Weintraub BD and Clark RE. Cardiopulmonary bypass and thyroid function: a "euthyroid sick syndrome." Ann Thorac Surg 1991; 52: 46-50.

10. Utiger RD. Altered thyroid function in nonthyroidal illness and surgery: to treat or not to treat? N Engl J Med 1995; 333: 1562 1563.

11. Chopra IJ. Euthyroid sick syndrome: is it a misnomer? J Clin Endocrin Metab 1997; 82: 329-334.

12. De Groot LJ. Dangerous dogmas in medicine: the nonthyroidal illness syndrome. J Clin Endocrin Metab 1999; 84: 151-164.

13. Moruzzi P, Doria E and Agostoni PG. Medium-term effectiveness of L-thyroxine treatment in idiopathic dilated cardiomyopathy. Am J Med 1996; 101: 461-467.

14. Mullis-Jansson SL, Argenziano M, Corwin S, Homma S, Weinberg $A D$, Williams $M$, et al. A randomized double-blind study of the effect of triiodothyronine on cardiac function and morbidity after coronary bypass surgery. J Thorac Cardiovasc Surg 1999; 117: 1128-1135.

15. Bettendorf M, Schmidt KG, Grulich-Henn J, Ulmer HE and Heinrich UE. Tri-iodothyronine treatment in children after cardiac surgery: a double-blind, randomised, placebo controlled study. Lancet 2000; 356: 529-534.

16. Hamilton MA, Stevenson LW and Fonarow GC. Safety and hemodynamic effects of intravenous triiodothyronine in advanced congestive heart failure. Am J Cardiol 1998; 81: 443447.

17. Malik FS, Mehra MR, Uber PA, Park MH, Scott RL and Van Meter $\mathrm{CH}$. Intravenous thyroid hormone supplementation in heart failure with cardiogenic shock. J Card Fail 1999; 5: 31-37.

18. Spooner PH, Morkin E and Goldman S. Thyroid hormone and thyroid hormone analogues in the treatment of heart failure. Coron Artery Dis 1999; 10: 395-399.

19. Kozdag G, Ural D, Vural A, Agacdiken A, Kahraman G, Sahin T, et al. Relation between free triiodothyronine/free thyroxine ratio, echocardiographic parameters and mortality in dilated cardiomyopathy. Eur J Heart Fail 7:113-118.

20. lervasi G, Pingitore A, Landi P, Raciti M, Ripoli A, Scarlattini M, et al. Low-T3 syndrome: a strong prognostic predictor of death in patients with heart disease. Circulation 2003; 107:708-713.

\footnotetext{
Authors Contribution:

AKN - designed the study, performed the laboratory tests and drafted the manuscript; SYL - analysed the data and drafted the manuscript; MKV - designed the experiments and reviewed the manuscript; RSS - contributed to the study design; RSA - contributed to the study design; MMB - contributed to the study design; VSK - contributed to the study design; MSM - designed the experiments and reviewed the manuscript.

Source of Support: Department of General Medicine, Mysore, India, Conflict of Interest: None declared.
} 